\title{
LOS REFORMISTAS DEL FRANQUISMO EN LAS CORTES: EL GRUPO PARLAMENTARIO INDEPENDIENTE ${ }^{1}$ \\ The reformists of the Franco regime at the Cortes: The Independent Parliamentary Group
}

\author{
MIGUEL ÁNGEL GIMÉNEZ MARTíNEZ \\ Universidad Autónoma de Madrid \\ miguel.gimenez@uam.es
}

Cómo citar/Citation

Giménez Martínez, M. Á. (2017).

Los reformistas del franquismo en las Cortes:

el Grupo Parlamentario Independiente.

Revista de Estudios Políticos, 179, 199-230.

doi: https://doi.org/10.18042/cepc/rep.179.07

\section{Resumen}

Entre los sectores que participaron en el proceso de cambio democrático en España, un papel destacado correspondió a los reformistas, figuras que, a la muerte de Franco, ocupaban puestos relevantes dentro de las instituciones de la dictadura y que protagonizaron diversos intentos de transformación del régimen en sentido democratizador. Algunos de estos reformistas, procuradores en Cortes, decidieron formar en la primavera de 1975 el Grupo Parlamentario Independiente, que constituyó un auténtico revulsivo en la mortecina existencia de la Cámara, dominada por el inmovilismo. A través de sus iniciativas, dinamizó la vida política española, y su influencia se pondría especialmente de manifiesto durante el debate de la Ley para la Reforma Política. Mediante el análisis de documentación inédita, este artículo trata de reconstruir la actividad del grupo y calibrar la contribución de sus miembros a la transición a la democracia.

1 El autor quiere agradecer a quien fuera uno de los fundadores del Grupo Parlamentario Independiente, Enrique Sánchez de León Pérez, la inestimable ayuda que ha prestado a este trabajo, cuya realización no habría sido posible sin la consulta de los documentos que obran en su archivo personal (en adelante, AESL). 


\title{
Palabras clave
}

España; franquismo; transición a la democracia; Cortes; grupos parlamentarios.

\begin{abstract}
Among the actors that took part in the process of democratic change in Spain, a prominent role was occupied by the reformists, leading figures who, at the death of Franco, held relevant positions within the dictatorship's institutions and carried out several attempts to transform the regime in a democratising sense. Some of these reformists, deputies of the Cortes, decided during the spring of 1975 to form the Independent Parliamentary Group (IPG), which served as an authentic wake-up call in the dull existence of the House, dominated as it was by ultraconservatism. Through its initiatives, the IPG re-invigorated Spanish political life, and its influence was patent during the discussion of the Political Reform Law. Through the analysis of unpublished documents, this paper aims to reconstruct the activity of the Group and assess the contribution of its members to the transition to democracy.
\end{abstract}

\section{Keywords}

Spain; Francoism; transition to democracy; Cortes; parliamentary groups. 


\section{SUMARIO}

I. INTRODUCCIÓN. II. LOS GRUPOS PARLAMENTARIOS EN LAS CORTES ORGÁNICAS. III. EL GRUPO PARLAMENTARIO INDEPENDIENTE: 1. Iniciativas parlamentarias. 2. La reforma política y el GPI. IV. CONCLUSIONES. BIBLIOGRAFíA.

\section{INTRODUCCIÓN}

El presente trabajo pretende analizar la actuación política del Grupo Parlamentario Independiente (GPI), que concentró dentro de las Cortes a los elementos reformistas de la élite política franquista en la etapa 1975-1977. Según nuestro análisis, pueden clasificarse como reformistas aquellos que defendieron públicamente posturas democratizadoras en el seno de la dictadura antes de la muerte de Franco y que posteriormente aceptaron — con distintos grados de intensidad- las consecuencias del proceso constituyente que culminó en $1978^{2}$. Desde nuestro punto de vista, el reformismo fue expresión de una reacción eminentemente pragmática ante la inminente desaparición de un régimen autoritario de signo derechista. La existencia de una alternativa reformista de estas características fue importante por tres motivos principales. En primer término, porque ayudó a acelerar la pérdida de legitimidad de la dictadura al oponerse a los proyectos meramente continuistas propugnados desde el poder. En segundo lugar, porque el reformismo aportaría hombres e ideas a los primeros Gobiernos de la monarquía, favoreciendo de forma destacada el tránsito a la democracia. Y, por último, porque llevó a cabo una importante contribución a la consolidación del proceso democrático al incorporar al mismo a amplios sectores previamente apolíticos o desmovilizados ${ }^{3}$.

Los antecedentes más o menos próximos del reformismo pueden encontrarse en el debate surgido en el seno del régimen franquista en relación con la elaboración de la Ley Orgánica del Estado, promulgada finalmente en 1967. Simplificando un tanto, puede decirse que, a partir de entonces, empezaron a surgir voces entre la clase dirigente partidarias de una institucionalización definitiva del mismo. Las distintas familias políticas del régimen sintieron la

2 La obra más completa que se ha publicado al respecto es la de Palomares (2006). Versiones más críticas sobre el papel de los reformistas en la transición las dan Molinero e Ysàs (2008: 183-282), y, sobre todo, Juliá (2010: 263-271).

3 Powell (1997: 247). 
necesidad de crear nuevos mecanismos que racionalizasen el reparto de poder entre la coalición gobernante, un reparto realizado de forma cada vez más arbitraria por un Franco cuyo deterioro físico era cada vez más grave $e^{4}$. Desde ese momento y, especialmente, tras el nombramiento de Luis Carrero Blanco como presidente del Gobierno, en junio de 1973, proliferaron las llamadas a favor de una apertura del sistema desde el interior del mismo.

Al menos tres núcleos reformistas con un mínimo de organización interna, así como numerosas iniciativas individuales, hicieron su aparición en aquellos momentos: el núcleo de los que podríamos denominar «azules»; otro formado en torno al exministro de Información y Turismo, Manuel Fraga, que fundaría el Gabinete de Orientación y Documentación S. A. (GODSA) en la primavera de $1973^{5}$, y el "grupo Tácito», de inspiración democristiana, que se daría a conocer en las mismas fechas mediante la publicación de artículos semanales en el diario católico $\mathrm{Ya}^{6}$.

El núcleo de los «azules» tuvo su origen en una reunión de consejeros nacionales del Movimiento celebrada en 1970 bajo la presidencia de Fernando Herrero Tejedor con el fin de exigir una mayor celeridad en la regulación del derecho de asociación política. Ello daría lugar a la creación del grupo de los "consejeros jóvenes», que se reunían periódicamente para unificar criterios de cara a su actuación en las instituciones políticas ${ }^{7}$. A iniciativa de estos, en la Pascua de Reyes de 1973, un total de 39 personalidades del régimen dirigieron una carta abierta a Franco en la que se subrayaba la necesidad de «diálogo y comunicación entre el pueblo y sus gobernantes mediante el responsable

4 En torno a esta cuestión, véanse Soto Carmona (2005) e Hispán Iglesias de Ussel (2006: 395 y ss.).

5 Entre sus componentes se encontraban Félix Pastor Ridruejo, Carlos Argos, José Manuel Romay Beccaría y Manuel Millán. Una reseña más exhaustiva de sus miembros puede encontrarse en GODSA, Boletín, 8-9, enero de 1977, pp. 24-27. Véase Fraga Iribarne (1980: 297-330). Según López Nieto (1988: 18), GODSA «fue un auténtico embrión de partido» y años más tarde se convertiría en «la plataforma más sólida con que contaba Fraga en su actividad política en 1975 y 1976».

6 La lista de integrantes de "Tácito» incluía, entre otros, a Rafael Arias-Salgado, Landelino Lavilla, Juan Antonio Ortega o José Manuel Otero Novas. Sobre este grupo véase Powell (1990). También son interesantes las memorias de otros miembros del grupo, como Osorio (1980: 24-27), Álvarez de Miranda (1985: 45-51) y Oreja (2011: 103).

7 El grupo lo componían personas de orígenes distintos: Rafael Cabello de Alba, Rodolfo Martín Villa, Marcelino Oreja, José Miguel Ortí Bordás, Gabriel Cisneros, Enrique Sánchez de León, Miguel Primo de Rivera, Nicolás Franco, Fernando Ybarra y Rafael Ruiz-Gallardón, en el despacho del cual se celebraban las reuniones. Véanse al respecto los testimonios de Ortí Bordás (2009: 128-130) y Sánchez de León (2008: 41). 
ejercicio de todas las libertades, y entre ellas la eficiente crítica de la acción política», exigiéndose asimismo "nuevos y más amplios cauces de participación política» ${ }^{8}$. Una parte importante del "grupo de los 39» impulsaría el Grupo Parlamentario Independiente, del que nos ocuparemos a continuación. Antes, sin embargo, es necesario realizar algunas consideraciones en torno a la particular naturaleza que adoptaron los Grupos Parlamentarios durante el franquismo.

\section{LOS GRUPOS PARLAMENTARIOS EN LAS CORTES ORGÁNICAS}

Los presupuestos que inspiran cualquier ordenamiento parlamentario en un Estado de derivación liberal brillaron por su ausencia desde el primer momento durante la dictadura de Franco?. El nuevo régimen surgido de la Guerra Civil originó la desaparición, entre otras instituciones, derechos y libertades, de los Grupos Parlamentarios. Dentro de la llamada «democracia orgánica», en 1942 se pusieron en pie unas Cortes que, de acuerdo con su Ley Constitutiva (LC) ${ }^{10}$, eran «el órgano superior de participación del pueblo español en las tareas del Estado» (art. 1). No eran, por tanto, representativas de los ciudadanos sino que se trataba de un colegio no electivo - al menos en su gran mayoría-, que no reflejaba el pluralismo político de la sociedad española ${ }^{11}$. Téngase en cuenta que las libertades públicas que permiten el ejercicio de la actividad política, como la libertad de expresión, el derecho a la información o el derecho de reunión y asociación, se encontraban fuertemente restringidas,

8 Citado en Payne (1987: 551). Entre los signatarios se hallaban Eduardo Navarro, Gabriel Cisneros, Antonio Castro Villacañas, Enrique Sánchez de León y José Miguel Ortí Bordás. Para una lista más detallada, véase Martín Villa (1984: 49).

9 Véanse Fernández Carvajal (1969), Zafra Valverde (1973), De Esteban et al. (1973), Menéndez Rexach (1979), Ferrando Badía (1984) y Giménez Martínez (2014).

10 Este texto sería modificado por la Ley de 9 de marzo de 1946, que introdujo algunos cambios en materia compositiva con vistas a la segunda legislatura, y por la Ley Orgánica del Estado, de 10 de enero de 1967, que la reformó sustancialmente. Véase Fernández Carvajal (1967). Sobre las Cortes franquistas, véanse los trabajos monográficos de Díaz-Nosty (1972), Iglesias Selgas (1973) y Giménez Martínez (2012).

11 Herrero de Miñón (1972: 41), en torno al papel que las Cortes desempeñaban en el conjunto del sistema, apuntaba que eran únicamente órgano del Estado y no de representación nacional. La significación histórica de aquella Cámara residió, a juicio de Baena del Alcázar (1999: 286), en ser lugar de encuentro de los poderosos del régimen. 
cuando no abiertamente prohibidas ${ }^{12}$. Por otro lado, los partidos políticos estaban penalmente sancionados, con lo que ninguna referencia a estos podía encontrarse en el sistema electoral de los pocos procuradores electivos. El carácter puramente nominal de estas Cortes se confirma, además, con la ausencia de autonomía normativa, por cuanto su Reglamento debía de elaborarlo «de acuerdo con el Gobierno» (LC, disposición adicional).

$\mathrm{Ni}$ siquiera los grupos que colaboraron con la dictadura, aquellos que articularon dentro del régimen autoritario lo que Linz denominaba "pluralismo limitado» ${ }^{13}$, aparecieron mínimamente organizados en el interior de la Cámara. Las llamadas "familias políticas» ${ }^{14}$ no pasaron de ser «entes sociales de contornos no siempre precisos, unas veces cercanos a grupos ideológicos, aunque carentes de estructura y organización para la competencia política, y otras veces más próximos a puros grupos de interés, pero que ni en un caso ni en otro pudieron identificarse exactamente con la imagen que estas denominaciones evocan en pura teoría o en su referencia a realidades comparadas» ${ }^{15}$.

Las Cortes franquistas dispusieron de un total de cuatro Reglamentos (publicados en los años 1943, 1957, 1967 y 1971) ${ }^{16}$ desde su constitución,

12 El Fuero de los Españoles, de 17 de julio de 1945, reconocía en sus arts. 12 y 16 la libertad de expresión y el derecho de reunión y asociación, respectivamente. Sin embargo, el propio Fuero, en su art. 33, la Ley de Principios del Movimiento Nacional, de 18 de mayo de 1958, y la extensa casuística del Código Penal limitaban sustancialmente estas libertades. El desarrollo legislativo de estas disposiciones no mejoraría la situación. La Ley de Prensa e Imprenta, de 18 de marzo de 1966, pese a su afán liberalizador, no hizo efectiva la libertad de expresión y el derecho a la información, al contemplar frente a las extralimitaciones una triple responsabilidad: penal, administrativa y civil. Las limitaciones y restricciones podían encontrarse también en la Ley de Reuniones de 1880, completada por una Orden de 1939, y en la Ley de Asociaciones, de 24 de diciembre de 1964. Véase sobre esta materia, Fernández Segado (1986: 709-710).

13 Linz (1964: 295).

14 Este concepto alcanzó gran relevancia a partir de la publicación del libro de De Miguel (1975: 143-233), en el que se clasificaba a quienes desempeñaron tales cargos en los siguientes grupos, que él denominaba «familias»: militares, primorriveristas, tradicionalistas, monárquicos, falangistas, católicos, integristas, tecnócratas y técnicos. Posteriormente se han expresado otras fórmulas para aludir a la misma realidad sociopolítica, tales como "personal político» (Viver Pi-Sunyer, 1978), «élites políticas» (Jerez Mir, 1982) y «cuadros políticos» (Sánchez Recio, 1996).

15 Garrorena Morales (1977: 142-143). Este autor recuerda además la práctica imposibilidad de identificar a aquellas "familias», es decir, de saber cuántas y cuáles fueron.

16 El texto de los mismos puede consultarse en Fernández Sarasola (2012: 378-458). 
consecuencia de la LC de 1942, hasta su extinción en 1977, tras la aprobación de la Ley para la Reforma Política. En ninguno de estos textos se contenía referencia alguna a grupos de procuradores que pudieran aproximarse al concepto de Grupo Parlamentario: las condiciones ambientales, como hemos visto, impedían tal posibilidad. Así, un fenómeno natural desde que empiezan a manifestarse los primeros colectivos ideológicos de parlamentarios, esto es, la proximidad entre sus miembros en los escaños de la Cámara, se impedía ya en el Reglamento de 1957, al establecerse que los procuradores tomarían asiento en el salón de sesiones «según el orden alfabético de sus primeros apellidos» (art. 62.2) ${ }^{17}$. El régimen nunca estuvo dispuesto a permitir uniones de parlamentarios, entre los que existieran afinidades, que constituyeran otras tantas unidades de maniobra para el ejercicio de su función, ya que le interesaba la desarticulación de la acción de los procuradores ${ }^{18}$.

Excepto en el primer Reglamento de este período, aparecían en todos los demás algunas menciones a los "grupos de procuradores» en obvia — por cuanto no podía ser de otro modo- referencia a las categorías establecidas en el art. 2 de la LC. Ya en el Reglamento de 1957 (art. 25.1) se afirmaba que «en cada Comisión estarían representados, dentro de lo posible, los diversos grupos que integran la Cámara». El Reglamento de 1967 repetía en aquel mismo artículo y de modo casi literal la referencia a los grupos de la Cámara. El último de los textos que estuvo en vigor, el de 1971, especificaría claramente el concepto de aquellos grupos —algo que nadie había llegado a dudarremitiéndose en varias ocasiones (arts. 25.1 y 2, 35.2 y 36.2) al aludir a ellos a cuanto se establecía en el art. 2 de la LC; en definitiva, se trataba de las distintas clases de procuradores - hasta un total de diez- incluidas en aquel precepto de la segunda de las Leyes Fundamentales franquistas, que las diferenciaba en función del título por el que accedían a las Cortes.

Solo en los momentos previos a la muerte de Franco pareció vislumbrarse la posibilidad de regular los Grupos Parlamentarios como reflejo del pluralismo político al que se encaminaba el país. Distintas proposiciones y sugerencias en este sentido estaban sometidas a estudio en la Comisión de Reglamento desde junio de 1975. Sin embargo, la reforma del Reglamento para dar cabida a los grupos políticos era una cuestión de voluntad política y ni el presidente de la

17 Fraga Iribarne (1959: 53) consideraba entonces que «no habiendo grupos políticos reconocidos en las Cortes, [éste] es el procedimiento más natural».

18 Giménez Martínez (2012: 206). Basta observar la actitud mostrada por las autoridades cuando se esbozó en 1968 un embrión de Grupo Parlamentario con motivo de las reuniones «trashumantes» emprendidas por los procuradores familiares. Véase DíazNosty (1972: 77-104). 
Cámara, Alejandro Rodríguez de Valcárcel, ni el Gobierno estaban interesados en modificar el funcionamiento de una institución que servía con fidelidad al propósito para el que se diseńó: servir de apoyo para la resolución de determinadas decisiones de relevancia política y "constitucional» ${ }^{19}$.

Hubo que esperar al inicio de la nueva etapa histórica que supuso la proclamación de Juan Carlos de Borbón como rey de Espańa para que se ordenara el "pluralismo" del régimen dentro de la Cámara por medio de grupos parlamentarios, coincidiendo con la primera regulación del derecho de asociación política tras la Guerra Civil ${ }^{20}$. El nuevo presidente de las Cortes nombrado por el monarca, Torcuato Fernández-Miranda, optó por materializar esta innovación mediante el instrumento procesal que tenía en sus manos: la vía interpretativa y supletoria. En efecto, el art. 18.23 del Reglamento de 1971 otorgaba a la Presidencia de las Cortes la facultad de interpretar y suplir dicho texto en los casos de duda u omisión. En ejercicio de aquella competencia, la máxima autoridad de la Cámara, previo informe favorable de la Comisión de Reglamento y de acuerdo con el Gobierno, dictó una Disposición regulando los grupos parlamentarios ${ }^{21}$.

En el preámbulo de dicha disposición, Fernández-Miranda afirmaba que el cumplimiento de las funciones encomendadas a las Cortes se vería potenciado al expresarse las opiniones de manera colectiva "y no meramente individual». El sistema para permitir aquella expresión no podía ser otro «que el vigente en la mayor parte de los Parlamentos y que cuenta con su antecedente en nuestra tradición histórica, de reconocer y regular el derecho a la formación de grupos entre los procuradores en razón de sus criterios políticos». Así, la normativa entonces emanada autorizaba la constitución de grupos parlamentarios «en función de tendencias o criterios políticos [...] y siempre bajo la autoridad de la Presidencia de las Cortes». El mínimo de procuradores necesarios para la formación de un grupo se fijaba en 50 (un número muy elevado si se tiene en cuenta que en aquel momento las Cortes se componían de 543 miembros). Se impedía a los procuradores formar parte de más de un grupo y

19 Soto Carmona (1995: 126). Esta función, que Tusell (2005: 171) llamó «resonadora», alcanzaba su máxima expresión en las contadas ocasiones en que Franco acudía a la Cámara a abrir las sesiones de una nueva legislatura o promulgar alguna de las Leyes Fundamentales.

20 La Ley 21/1976, de 14 de junio, sobre el Derecho de Asociación Política, es posterior en solo tres meses a la Disposición de la Presidencia de las Cortes que analizamos a continuación.

21 El texto completo de esta Disposición se encuentra en el Boletín Oficial de las Cortes Españolas (BOCE), 1489, de 9 de marzo de 1976, p. 35 989. Un comentario de la misma en Aguiló Lúcia (1976). 
se establecía la publicación, en el $B O C E$, de los nombres de los miembros de cada agrupación — cosa que nunca se hizo- así como de la declaración o "programa delimitador de sus fines» que estos debían redactar al formarla. El régimen interior de cada grupo sería acordado autónomamente, y debería respetar, en todo caso, la libertad de voto y el derecho de cada uno de sus componentes a intervenir en la formación de la voluntad del grupo, a elegir los órganos de dirección, a explicar su voto y a abandonarlo. Por último, la Disposición otorgaba a la Presidencia de la Cámara la posibilidad de autorizar "con carácter provisional» la constitución como grupos parlamentarios de aquellos que tuvieran más de 25 miembros y cumpliesen los demás requisitos exigidos.

Como puede apreciarse, esta normativa concedía amplias posibilidades de intervención al presidente de las Cortes en la vida de los grupos, sometidos siempre a su autoridad. Además, precisaba aspectos del funcionamiento interior de aquellos que en unos casos por ser obvios (el derecho de abandonar el grupo o de participar en sus actividades) y en otros por resultar difícilmente practicables (la libertad absoluta de voto), chocan con cualquier regulación moderna de las fracciones que normalmente, con muy buen criterio, los silencia. Por otra parte, no deja de sorprender que simultáneamente al reconocimiento de los grupos parlamentarios no se procediera a una reforma del Reglamento de las Cortes, ya que las competencias de aquellos, en cuanto tales, eran inexistentes ${ }^{22}$. Así pues, hay que afirmar que los grupos parlamentarios del franquismo «solo se parecían a los propios de cualquier Cámara democrática en el nombre» ${ }^{23}$. Como estableció Torres del Moral, "la regulación no contemplaba Grupos Parlamentarios, sino meros agregados ocasionales de procuradores ${ }^{24}$.

Ahora bien, si desde el punto de vista jurídico la regulación de los grupos parlamentarios fue claramente insuficiente, desde una perspectiva política adquiriría gran importancia en el contexto del proceso de transición a la democracia. Así, los grupos fueron un factor de racionalización del trabajo de la Cámara al servicio de la reforma política. Y, al mismo tiempo, hicieron que

22 Pérez-Serrano Jáuregui (1989: 176) reconocía que esta regulación «implicaba un notorio avance en las aspiraciones democráticas», pero, al mismo tiempo, consideraba que «ese afán súbitamente democrático constituía un auténtico sarcasmo en un momento histórico en que continuaba siendo delito la pertenencia a un partido político».

23 Saiz Arnáiz (1989: 74). En la misma línea se manifiesta García Guerrero (1996: 112 113). Morales Arroyo (1990: 98) habla de su «fracaso» por la «ausencia de un verdadero pluralismo político».

24 Torres del Moral (1981: 30). 
aquella resultara mucho más manejable por la Presidencia, porque la labor de captación y control de los procuradores que estos realizaban resultaba mucho más fácil y eficaz al disponer las Cortes de una estructura grupal que le dispensaba tener que actuar sobre miembros individuales y dispersos ${ }^{25}$.

Partiendo del hecho de que las Cortes no eran un bloque monolítico sino que en su seno coexistían "corrientes quietistas y corrientes dinámicas»" ${ }^{26}$, con esta medida se fortalecieron las posturas de los procuradores partidarios del cambio para que pudieran hacer oír su voz, de forma organizada y por lo tanto más efectiva, frente a los sectores inmovilistas que mantenían bajo su control el funcionamiento de la Cámara. Frente a la opinión generalizada de que las Cortes eran un obstáculo insalvable para el cambio, lo que Fernández-Miranda pretendía era integrarlas en la reforma ${ }^{27}$. Además, los grupos debían servir para simplificar los debates y agrupar las enmiendas, algo que iría en beneficio de una agilidad reformadora exigida por la complicada coyuntura política, económica y social del momento.

Las medidas fueron bien acogidas por los sectores reformistas ${ }^{28}$, que no se engañaron sobre la finalidad de las mismas: no era un intento de dotar de nueva vida a las mortecinas Cortes, sino de romper el gregarismo imperante entre sus miembros. Así, el letrado mayor de la Cámara, Manuel Fraile Clivillés, afirmó que con la medida por primera vez las Cortes «iban a empezar a parecerse a un Parlamento europeo» y que ya nadie iba a hablar «a título personal, sino en función de un grupo que le va a respaldar». A su juicio, la opinión pública sabría ahora «a qué atenerse y por dónde van los tiros», porque "precisamente los partidos políticos nacen como consecuencia del agrupamiento de parlamentarios frente a la competición electoral ${ }^{29}$. En la misma línea, el procurador familiar por Segovia, Andrés Reguera, reconocía que los grupos iban a servir «de preparación para el día en que puedan constituirse partidos políticos» ${ }^{30}$.

Al amparo de esta normativa, que tuvo una buena acogida por parte de los procuradores, se constituyeron un total de seis grupos parlamentarios, que

25 Ortí Bordás (2009: 230-231).

26 Negrín (1976: 3).

27 Como dejó escrito Fernández-Miranda (1995: 320) en una nota manuscrita: «Busco demostrar que estoy dispuesto a reconocer las tendencias y fundar el sentido del pluralismo asociativo en las Cortes. Quiero ver qué grupos hay y si son posibles; y quiero ver hasta dónde es útil para los fines de la reforma el divide y vencerás frente a los que pretenden monopolizar y dirigir como budas».

28 Con alguna excepción, como la de Meliá (1976).

$29 Y a, 8-2-1976$, p. 3.

30 Pueblo, 9-2-1976, p. 11. 
formalizaron su existencia antes incluso de que se dictase la Disposición que permitía su creación porque la Comisión de Reglamento manifestó oficiosamente a los procuradores que tal posibilidad iba a hacerse realidad de forma inminente ${ }^{31}$. De todos ellos, el más cercano al «búnker» fue el de Acción Institucional, partidario de la continuidad con el régimen, que integraba a falangistas y tradicionalistas históricos como Raimundo Fernández-Cuesta, Pilar Primo de Rivera, Antonio María de Oriol o José Luis Zamanillo. Otros tres, Unión del Pueblo Español, el Laboral-Democrático y el Regionalista, agrupaban a diferentes sectores de la derecha franquista que toleraban una cierta renovación del régimen representativo para hacerlo "políticamente auténtico", pero siempre «dentro de las Leyes Fundamentales y de los principios ideológicos del Movimiento Nacional». Por su parte, Unión Democrática Española reunió a los procuradores pertenecientes a la asociación política homónima de inspiración católica que dirigía Alfonso Osorio. Atenazado por las disensiones internas, el sector más derechista del grupo, siguiendo a Federico Silva y Alberto Monreal, terminó escindiéndose ${ }^{32}$.

\section{EL GRUPO PARLAMENTARIO INDEPENDIENTE}

El único grupo de talante claramente reformista fue el Grupo Parlamentario Independiente, que presentó el programa delimitador de sus fines el 25 de febrero de $1976^{33}$. En él, sus integrantes afirmaban su «talante democrático, social y progresista" y se definían como una colectividad de «distintas tendencias y pensamientos», pero reunidos bajo «una identidad de fines parlamentarios y políticos, conducentes a acelerar el proceso democratizador del país» ${ }^{34}$. Un proceso que debía empezar "por una profunda democratización de las Cortes», mediante «la reforma de las Leyes Fundamentales» y el establecimiento de un Congreso "por sufragio universal, secreto, libre, igual y directo",

31 Arriba, 5-2-1976, p. 5.

32 Archivo del Congreso de los Diputados (ACD), serie general, caja 3691, carpetas 1-5.

33 «Grupo Parlamentario Independiente. Programa delimitador de sus fines», Madrid, 25 de febrero de 1976. AESL, carpeta GPI. Junto al programa, se comunicaba la lista de los integrantes del Comité de Coordinación del grupo: Jesús Aparicio Bernal, Gabriel Cisneros, Rubens Henríquez, Carlos Iglesias, Ángel Martínez Fuertes, José Luis Meilán, Rafael de Mendizábal, Enrique Sánchez de León, Jesús Sancho Rof y David Pérez Puga, el último de los cuales actuaba como portavoz.

34 Una idea reiterada después por Enrique Sánchez de León en una entrevista publicada en la Hoja del Lunes (de Barcelona) (26-5-1975): «La procedencia de sus miembros es diversa, pero su meta es única». 
y una segunda Cámara «de actos territoriales, sindical, profesional y de entidades representativas». Como corolario de todo ello se reclamaba «el reconocimiento de agrupaciones políticas o partidos, de libre actividad, sin más límites que [...] la democracia constitucional».

En materia sindical, el programa del GPI abogaba por «sindicatos obreros y organizaciones patronales independientes y ambos con autonomía frente a la Administración, organizados democráticamente», y estimaba que el «soporte de la democracia» eran los derechos fundamentales, que a su juicio debían «vincular a los poderes legislativo, ejecutivo y judicial a título de derecho directamente aplicable». En este sentido, el Estado debía, «además de declarar y aplicar libertades formales, [...] resolver todas las necesidades materiales y espirituales del ser humano». El GPI propugnaba, además, la «independencia» del Estado «respecto de las Iglesias legalmente establecidas en el país», así como el derecho de asociación y reunión para posibilitar «una convocatoria electoral en la que puedan y deban participar cuantas corrientes de opinión acepten la democracia constitucional y para legalizar una oposición política con función de crítica objetiva a las opciones del Gobierno».

En cuanto a la soberanía nacional, entendían que «le corresponde al pueblo como titular exclusivo», quedando reservado al rey una "función arbitral». El documento programático finalizaba con una demanda al Gobierno de "programas coherentes en plazos concretos» que contemplaran «la integración en Europa», la regulación de "las autonomías regionales» y la aplicación de todas las «libertades civiles básicas» para alcanzar la "concordia nacional»; y, en el campo social, «la potenciación de las formas de propiedad comunitaria o colectiva", la continuada "socialización del suelo" y la consecución de unos objetivos «también socializantes para la cultura y la educación».

Cuando se produjo la constitución formal del GPI, sus integrantes tenían a sus espaldas una breve, pero sin duda apreciable, experiencia como entidad colectiva. Y es que el Grupo Parlamentario Independiente llevaba funcionando realmente desde marzo de 1975 — un año antes, por tanto, de que se reglamentara su existencia en el seno de las Cortes-, como consecuencia del germen que supuso el inicial grupo de consejeros nacionales jóvenes y de la necesidad sentida por sus integrantes de coordinar mejor su actuación dentro de las instituciones. Aunque al principio contaba con poco más de veinte procuradores, con el paso del tiempo sus efectivos se incrementaron notablemente hasta alcanzar los 47 miembros en noviembre de $1976^{35}$.

35 Se produjeron también algunas bajas, como las de José María Aguirre González, Luis Mombiedro de la Torre y Miguel Primo de Rivera, que abandonaron el grupo en marzo de 1976; Joaquín Fernández López, que pasó a la órbita del Grupo de Acción 
La biografía de la mayor parte de los procuradores que componían el GPI se había desarrollado en el ámbito del Movimiento Nacional, estructura específicamente política de la dictadura. Se trataba de figuras que habían dado sus primeros pasos en la vida pública dentro del Frente de Juventudes o del Sindicato Español Universitario, aunque también había personas procedentes de la Asociación Católica Nacional de Propagandistas o del monarquismo, que ahora accedían a la Cámara como representantes de la Organización Sindical (José Ramón Alonso, Francisco de la Caballería, Jaime Campmany, Antonio Castro Villacañas, José Comesańa, Baldomero Fernández Calviño, Julio García Valdés, Federico Gerona de la Figuera, Francisco Guerrero, Carlos Iglesias Selgas, Alberto Manzarbeitia, Angel Martínez Fuertes, Rafael Mateo Tarí, Salvador Morales, Antonio Navarro, Pedro Perpinán, Daniel Regalado, Jesús Sancho Rof y José María Socías ${ }^{36}$ o como consejeros nacionales (Gabriel Cisneros, Rodolfo Martín Villa, Eduardo Navarro, José Miguel Ortí Bordás y Enrique Sánchez de León) ${ }^{37}$. Junto a ellos se encontraban procuradores que habían obtenido su escaño en las Cortes por el llamado «tercio familiar» (Jesús Aparicio Bernal, Félix Calvo Ortega, Jesús Ezponda, Martín Fernández Palacio, Alberto Jarabo Payá, José Manuel Liaño, José Luis Meilán, Josep Meliá, Rafael Merino, Julián Muro, David Pérez Puga, Antonio Rosón y Antonio Segovia) ${ }^{38}$ o por el de Administración Local (Paulino Buchens, Alfonso Díaz de Bustamante, Miguel Gamazo, José Manuel Martínez Aguirre, Javier Perea y Abelardo Sánchez) ${ }^{39}$. El grupo se completaba con los representantes de las asociaciones, colegios profesionales y cámaras de comercio (Rubens Henríquez, José Lladó y José Elías Gallegos) ${ }^{40}$ y con un procurador designado directamente por el jefe del Estado (Rafael de Mendizábal) ${ }^{41}$.

Lo más relevante y políticamente significativo para distinguir a este grupo es el factor generacional, que como estudiaran Carr y Fusi, «fue un componente decididamente importante del aperturismo» ${ }^{42}$. La media de edad de los procuradores que integraron el GPI era, en 1976, de 47 años, mientras que la

Institucional y terminaría votando en contra del proyecto de Ley para la Reforma Política; Eusebio Hualde y Jesús Lample, que se trasladaron al Grupo LaboralDemocrático, y Manuel Pérez Olea, que se marchó al Grupo de Unión del Pueblo Español. Véase ACD, serie general, caja 3691, carpeta 6.

36 ACD, serie documentación electoral, caja 196-4.

37 ACD, serie documentación electoral, caja 196-2.

38 ACD, serie documentación electoral, caja 198-2.

39 ACD, serie documentación electoral, caja 197.

40 ACD, serie documentación electoral, caja 199-1.

41 ACD, serie documentación electoral, caja 199-2.

42 Carr y Fusi (1979: 48). 
del conjunto de procuradores en Cortes era de 57 . Solo siete procuradores presentaban una fecha de nacimiento anterior a 1922 y, por tanto, estaban en condiciones de haber participado en la Guerra Civil, mientras que los restantes cuarenta (el $85 \%$ ) eran niños durante el conflicto o habían nacido después de él. Además, el $53 \%$ de ellos se hallaba ante su primera experiencia «parlamentaria», lo que contrasta con la reducida renovación general de la Cámara, que respecto a la anterior legislatura solo había alcanzado al 29,2\% de los procuradores. Desde el punto de vista profesional también se observa un claro contraste entre los integrantes del GPI y la "clase política cerrada» ${ }^{43}$ del franquismo, en la que la circulación o movilidad era mínima y las pautas de reclutamiento estaban más bien establecidas. Así, el 63\% eran profesionales del derecho, frente al 27,3\% del total; el 52\% eran funcionarios (catedráticos, fiscales, magistrados, letrados, inspectores, técnicos de la Administración, etc.), por el $28 \%$ del conjunto de las Cortes, y el $38 \%$ desarrollaban actividades empresariales, por el $18 \%$ del total. Por último, es elocuente que en el Grupo no hubiera ningún militar, frente al $6,4 \%$ que significaban en las Cortes ${ }^{44}$.

Estos datos ayudan a entender mejor que el GPI incorporaba a una élite política de nueva generación, que alcanzó una toma de conciencia sobre la auténtica situación política del país, constituyó el germen de un clima de opinión más libre y poroso a la realidad e hizo posible la articulación de una incipiente posición política basada, en primer lugar, en la apertura y en una segunda fase en el deseo de un proceso de desarrollo político que superase la mera liberalización del franquismo en la línea de una democratización completa y homologable. Una generación mayoritariamente dialogante y europeísta, convencida de que la nueva y modernizada sociedad española de los setenta exigía un sistema político igualmente nuevo y moderno, equiparable al de las democracias occidentales. Lo que no era obstáculo para que ocupasen cargos públicos, aceptasen la legalidad de la dictadura y, en suma, asumiesen las responsabilidades que se derivaban de su integración política en el régimen.

\section{INICIATIVAS PARLAMENTARIAS}

El GPI nació con la idea de «extraer todas las posibilidades democráticas» a las Leyes Fundamentales, «sin descartar, por otra parte, la reforma constitucional». Fruto de este propósito fueron las múltiples iniciativas que impulsó,

43 Jerez Mir (1996: 267).

44 Los datos de los procuradores han sido extraídos de Repertorio biográfico de procuradores en Cortes (1973), Giménez Martínez (2012: 158-162) y Díaz-Nosty (1972: 165-178). La información sobre los funcionarios en Bañón Martínez (1978: 169). 
amparadas en la «realidad de la vida política y social del país» ${ }^{45}$, que abarcaron prácticamente todos los ámbitos: desde la situación internacional a la crisis socioeconómica, pasando por las relaciones interorgánicas o la extensión de los derechos y libertades.

La primera de ellas fue la presentación, el 22 de mayo de 1975, de una proposición de ley sobre reforma del Reglamento de las Cortes, cuyo objetivo fundamental era conseguir que estas, en su cometido y funcionamiento, fueran equiparables «a los Parlamentos de los países occidentales» y estuvieran en condiciones de «instrumentar la revisión de las Leyes Fundamentales». Para ello, se pedía que el Pleno de la Cámara se configurara como «órgano legislativo habitual y permanente», así como una "democratización de los procedimientos [...] legislativos y de fiscalización». El GPI consideraba que, al objeto de hacer realidad esta aspiración, era necesario, por un lado, «limitar interferencias gubernativas» en la "labor de enjuiciamiento y control del Ejecutivo», la cual debía llegar al extremo de obligar al Gobierno a «someter a debate su programa y los informes sobre la situación general del país», y, por otro, limitar el «abuso que supone la utilización de decretos leyes al margen de los estrictos casos de urgencia ${ }^{46}$.

Poco después, el 10 de junio de 1975, el GPI elevó un ruego al Gobierno en el que se solicitaba la constitución de una Comisión especial a fin de «obtener datos objetivos y fehacientes» que condujeran a una proposición de ley de reforma de la Universidad española. El Ejecutivo respondió considerando «innecesaria» la creación de dicha Comisión, amparándose una vez más en «la proximidad del término de la Legislatura” y remitiéndose a lo previsto por el art. 8 de la Ley General de Educación, que establecía que al menos «anualmente el Gobierno informará a las Cortes de la aplicación de la presente Ley [...] y propondrá las modificaciones que estime necesarias para su actualización ${ }^{47}$.

45 «Exposición a la Presidencia de las Cortes con motivo de la designación de nuevo presidente de la Cámara», Madrid, 10 de diciembre de 1975. AESL, carpeta GPI.

46 «Proposición de ley sobre reforma del Reglamento de las Cortes», Madrid, 22 de mayo de 1975. AESL, carpeta GPI. La proposición, que también demandaba la constitución reglamentaria de Grupos Parlamentarios, fue recibida con frialdad por el presidente de las Cortes, Alejandro Rodríguez de Valcárcel, quien no la tomó en consideración en base a hallarse «la atención de la Cámara [...] absorbida hasta el término de la presente Legislatura por otros proyectos ya en curso». Como concesión se anunció, no obstante, la creación de una ponencia de estudio para la mejora del procedimiento parlamentario, que nunca llegó a reunirse y posteriormente quedó sin efecto. Véase BOCE, 1446, de 10 de julio de 1975, p. 35114 .

47 «Ruego solicitando la constitución de una Comisión especial parlamentaria para investigar e informar sobre la situación en que se encuentra la Universidad española», Madrid, 10 de junio de 1975. AESL, carpeta GPI. 
La actividad del Grupo Parlamentario Independiente conoció un salto cualitativo con la remisión, el 14 de junio de ese mismo año, de una petición motivada en la que se solicitaba la convocatoria de un Pleno extraordinario de las Cortes para que el Gobierno informara de diversos aspectos de la política exterior ${ }^{48}$. El escrito elevado al Ejecutivo criticaba "los vacíos informativos» sobre la materia, que habían provocado «dudas, inquietudes y desconcierto entre los ciudadanos», y reclamaba noticias sobre las relaciones mantenidas con Estados Unidos, los países del Este, la Comunidad Europea y Marruecos, con el telón de fondo del proceso de descolonización del Sáhara. En cuanto a la primera de estas cuestiones, y de cara a las negociaciones en curso para la renovación del acuerdo hispano-norteamericano, el GPI pedía al Gobierno que luchara por mejorar el mismo, incluyendo en él la mutua defensa contra cualquier enemigo exterior "sin reservas, limitaciones ni prioridades», reduciendo las instalaciones militares estadounidenses «al mínimo indispensable» y eliminando la concesión de extraterritorialidad jurisdiccional para los miembros de las Fuerzas Armadas estadounidenses. En caso de obtenerse «resultados pobres e insatisfactorios», proseguía la petición, «habría que pensar seriamente en la alternativa de renuncia a cualquier acuerdo, [...] para salvaguardar nuestra independencia y neutralidad en un posible conflicto bélico de carácter mundial».

En relación a los países comunistas, los miembros del GPI defendían «un criterio de estricto pragmatismo político, distinguiendo a las naciones de sus sistemas de Gobierno y de sus ideologías políticas», a fin de poner en práctica "una política exterior claramente abierta y realista». Sobre las «inacabables negociaciones» para el ingreso de España en la Comunidad Europea, se exigían al Gobierno pasos para superar el «hasta ahora insalvable obstáculo de la insuficiente democratización de nuestro sistema político, [...] partiendo de nuestra irrenunciable vocación europeísta». Finalmente, el GPI pedía información al Gobierno sobre las relaciones con Marruecos, que «distan mucho de ser las normales entre países con intereses comunes y con fuertes vínculos de comunicación, tal como largos ańos de manifestaciones ingenuas o triunfalistas han hecho ver a los españoles». Junto a diversas cuestiones en torno a los límites de las aguas internacionales y la ruptura del tratado de pesca, se formulaban algunas consideraciones sobre el conflicto del Sáhara ${ }^{49}$.

48 «Petición motivada para la convocatoria de un Pleno extraordinario de Política Exterior», Madrid, 14 de junio de 1975. AESL, carpeta GPI.

49 A pesar de lo detallado de la petición, el Gobierno, una vez más, rechazó la iniciativa del GPI, aduciendo que hacía menos de un mes que el ministro de Asuntos Exteriores (Pedro Cortina) había comparecido en la Comisión homónima de las Cortes, donde 
El 16 de julio de 1975, el GPI presentó una nueva proposición de ley, esta vez destinada a levantar las trabas que impedían el libre ejercicio de los derechos de reunión y manifestación. En virtud de su articulado, quedaba eliminaba la necesidad de autorización previa por parte de la Administración cuando se congregaran más de veinte personas. Y ello porque, a juicio de los proponentes, «en un Estado de derecho, debe ser única condición válida para limitar el ejercicio del derecho de reunión el que deba ser pacífica» ${ }^{50}$.

Tras el receso veraniego, el GPI volvió a la carga con una moción, firmada el 16 de octubre de 1975, en la que se repasaba la «situación política española ${ }^{51}$ y se instaba al Gobierno a tomar medidas de muy distinta índole: «revisar» el Decreto Ley de agosto de 1975 sobre prevención del terrorismo; restablecer plenamente la jurisdicción ordinaria "para todos los delitos no específicamente militares»; reformar el Código Penal y las leyes penales relativas a la seguridad del Estado, «acomodándolos a los cambios acaecidos en la sociedad espańola»; promulgar una ley electoral "que garantice la plena participación de los ciudadanos»; perfeccionar una normativa sobre asociaciones "que posibilite el juego político de todos los ciudadanos»; modificar el sistema fiscal, sin aplazamiento «bajo el pretexto de trámites o estudios, que se han revelado como fórmulas dilatorias»; impulsar una reforma de la empresa, «que suponga una auténtica cogestión y que promueva una participación efectiva en los beneficios y en las plusvalías»; reconocer las regiones, «soslayadas en la reciente Ley de Bases de Régimen Local», y replantear las relaciones internacionales "con criterio de estricto pragmatismo político".

En diciembre de 1975, poco después de la proclamación de Juan Carlos I, el GPI elevó al nuevo presidente de las Cortes, Torcuato Fernández-Miranda, una moción similar a la presentada en octubre, pero ampliada en su contenido y con un tono más acentuadamente reformista y democratizador ${ }^{52}$. La oportunidad del texto se apoyaba en «el caudal de esperanza» despertado por el acceso al trono del nuevo rey, que exigía "la aplicación de una política imaginativa y dinámica». La moción solicitaba, en primer lugar, el «restablecimiento de las

había informado «ampliamente sobre la problemática internacional y desde esa fecha no han variado las circunstancias en que se desarrolla la política exterior del país». Véase BOCE, Diario de Sesiones de las Comisiones, 508, de 6 de mayo de 1975.

50 «Proposición de ley sobre derecho de reunión», Madrid, 16 de julio de 1975. AESL, carpeta GPI.

51 "Moción sobre la situación política española», Madrid, 16 de octubre de 1975. AESL, carpeta GPI.

52 «Moción sobre la situación política española y las medidas que podrían adoptarse por el Gobierno de la Nación para resolver los problemas nacionales más urgentes», Madrid, diciembre de 1975. AESL, carpeta GPI. 
libertades y derechos», mediante la supresión de la autorización gubernativa previa para reuniones, manifestaciones, conferencias, disertaciones y demás formas de expresión; la eliminación de la facultad extraordinaria de retirar los pasaportes; la adopción de «una política más liberal» en materia de prensa y la conversión de la televisión en un "marco adecuado a la polémica». Por otro lado, sobre las asociaciones políticas aprobadas en 1974, el Grupo solicitaba un ensanchamiento de su marco, incluyendo «a todos los españoles que se manifiesten dispuestos a respetar la ley y a actuar democráticamente».

Otro objetivo del GPI expresado en esta moción era lograr una «efectiva reconciliación nacional», lo que solo se lograría cuando "no quede un solo preso por delitos de asociación ilegal, reunión no pacífica, manifestaciones públicas, propagandas ilegales o huelgas de obreros». En ese sentido, el indulto concedido tras el ascenso al trono del rey Juan Carlos se consideraba un paso en ese sentido, pero no suficiente: era necesaria una amnistía, "concebida como medio de pacificación y de integración nacional». Otras medidas complementarias para garantizar esta aspiración eran la «expresa derogación» del Decreto-Ley de agosto de 1975 sobre prevención del terrorismo, «el reconocimiento de las remuneraciones de los mutilados de guerra a los que sufrieron mutilaciones en la zona republicana y de pensiones a las viudas de quienes murieron sirviendo en las filas del Ejército Español Republicano» y la concesión de las «indemnizaciones correspondientes» a los "funcionarios sancionados por causas de la guerra y a sus viudas e hijos».

No menos importante era el punto de la moción referido a la «reforma constitucional». De este modo, se pedía que en la nueva "Constitución del Reino, en la que se refundan las Leyes Fundamentales» apareciera «una Cámara formada exclusivamente por los representantes de los ciudadanos», introduciendo «una proporcionalidad entre los procuradores y la población» y reconociendo el derecho al voto a los mayores de dieciocho años. Además, se demandaba que las Cortes tuvieran "competencia en el cese del presidente del Gobierno, que no debe ser cometido exclusivo del Consejo del Reino, el cual tampoco debe tener en su nombramiento otra misión que la de consulta previa». Este último órgano quedaría reducido a una "Diputación Permanente de las Cortes», cuyos miembros estarían «obligados a comportarse de acuerdo con las decisiones adoptadas por las Cortes y dar cuenta a estas de sus decisiones».

Sobre política laboral, resulta muy significativa la condena que se hacía a la «descalificación que se realizó a partir del otoño de 1936 de los que en otros tiempos lucharon con honradez por el mundo del trabajo». De forma paralela, se pedía una amplia reforma de la Organización Sindical que incluyera la "completa y absoluta» autonomía e independencia de las organizaciones de trabajadores, «dentro del respeto a la legalidad, que no debe ser obstáculo a un racional ejercicio de la lucha obrera». En cuanto a la negociación colectiva, se 
apuntaba que «debe ser libre, sin topes ni límites de ninguna clase y sin intervenciones administrativas que desvirtúan lo acordado [...], un nuevo sacrificio de los económicamente más débiles es injustificable». La reforma sindical quedaría completa, a juicio del GPI, con la legalización «de las huelgas profesionales de rama" y la eliminación de "los preceptos tajantes sobre despido — que debería quedar al arbitrio de los tribunales- en casos de huelga».

El último gran tema de esta moción tenía que ver con la reforma del sistema sancionador, que «no guarda correspondencia con las actuales convicciones sociales». En este sentido, se reiteraban algunas consideraciones ya expresadas en el texto de 16 de octubre de 1976, como la supresión de «la jurisdicción militar en el enjuiciamiento del terrorismo y otras delitos no específicamente militares» y la sustitución "en todos los casos de la pena de muerte por la de reclusión perpetua y, esta, en ningún caso figure como pena única».

En los primeros días de enero de 1976, el GPI presionó mediante un ruego para que el presidente del Gobierno, Carlos Arias Navarro, compareciera ante las Cortes no solo para exponer su programa, sino para «someterlo a debate» ${ }^{53}$. Efectivamente, Arias acudió a las Cortes el 28 de enero ${ }^{54}$, pero no hubo tal debate: el jefe del Ejecutivo se limitó a leer un discurso que fue mal recibido por la opinión pública e incluso por algunos de sus propios ministros $^{55}$. El GPI elaboró entonces un comunicado, que fue remitido a los medios de comunicación, en el que mostraba su disconformidad "con algunos extremos fundamentales» de la intervención del presidente ${ }^{56}$. El documento consideraba, en primer lugar, «que debe cuanto antes sustituirse la simple tolerancia de las actividades políticas por la regulación legal de estas, modificando en cuanto sea necesario el actual ordenamiento jurídico». Y ello porque «la existencia y libre actuación política» era «tan importante para el país como la del Gobierno», y no resultaba «lógico continuar forzando a la clandestinidad o reduciendo al paternalismo tutelar la existencia de legítimas opciones políticas».

53 «Ruego recabando la comparecencia del presidente del Gobierno ante el Pleno de las Cortes sometiendo a debate el programa de Gobierno». Madrid, enero de 1976. AESL, carpeta GPI.

54 BOCE, Diario de las Sesiones del Pleno (DSP), 23, de 28 de enero de 1976, pp. 2-16.

55 Areilza (1977: 84) comentó que «la Monarquía no puede consolidarse con un hombre [...] vacilante y temeroso, que sigue creyendo que Franco está vivo y dirige el país desde la tumba»; y Osorio (1980: 64) apuntó cómo «en los ambientes de la calle soplaba el viento de la decepción» y «solo los sectores que creían en la parálisis política estaban satisfechos».

56 «Comunicado del Grupo Parlamentario Independiente sobre el discurso del presidente del Gobierno", Madrid, 30 de enero de 1976. AESL, carpeta GPI. 
Sobre la reforma administrativa, el Grupo demandaba la «implantación de rigurosas incompatibilidades» y una acción más decidida a la hora de "perseguir y eliminar toda arbitrariedad y cualquier corruptela en la función pública». En torno al fenómeno regional, el GPI deseaba «un tratamiento más profundo y avanzado», que desembocara en «el debido reconocimiento de los hechos diferenciales». Por último, reprochaba que el presidente del Gobierno no hubiera realizado «un esfuerzo de imaginación y de presencia» que resultara «sugestivo para la juventud». El comunicado finalizaba con el ofrecimiento de colaboración parlamentaria por parte del Grupo, pero sin renunciar a "críticas y proposiciones de ley, como viene haciendo desde su constitución».

Ante la nueva comparencia del presidente del Gobierno en Televisión Española, el 28 de abril de 1976, el GPI volvió a publicar un comunicado, más duro que el anterior, en el que "consideraba insuficientemente tratadas" algunas cuestiones: que el Congreso previsto «no represente ideologías políticas de los ciudadanos a través de los partidos»; que no se definiera «la responsabilidad parlamentaria del Gobierno"; que la reforma sindical no concretara «lo que debía quedar a la determinación democrática de obreros y empresarios»; que el problema regional se circunscribiera «a las comisiones administrativas creadas al efecto», cuando "hubiera sido oportuno definir el alcance de las autonomías regionales»; que no se contemplara como viable «la posibilidad de contar una oposición democrática», y, finalmente, que el presidente se centrara en hablar de las huelgas, "sin llevar aparejada una condena de otras conductas antisociales, tales como la evasión de capitales, que afecta también gravemente a la economía nacional» ${ }^{57}$.

\section{LA REFORMA POLÍTICA Y EL GPI}

La posibilidad de una transición desde dentro del régimen no era una novedad a la altura de 1975. La habían esgrimido los diferentes núcleos reformistas y muchos autores habían reflexionado sobre una mutación democrática del régimen ${ }^{58}$. Así, Miguel Herrero de Miñón había publicado un libro en 1972 en el que, a partir de la soberanía del rey, se entresacaba la posibilidad de que el monarca pudiera convocar un referéndum de alcance constitucional

57 "Contacto 36», Madrid, 29 de abril de 1976. AESL, carpeta GPI.

58 Fraga Iribarne (1971) no había llegado tan lejos, limitándose a poner sobre la mesa el concepto de «desarrollo político», que aplicado al franquismo significaba una cierta liberalización del régimen (apertura de cauces de participación popular, integración en el sistema de la oposición más moderada): a su juicio, se trataba de poner al día las instituciones, que habían quedado anticuadas frente al desarrollo económico del país. 
que permitiría, según sus propias palabras, y entre otras cosas, transferir «las competencias de las Cortes al pueblo" " ${ }^{59}$. Por su parte, Jorge de Esteban y sus colaboradores hicieron al año siguiente una interpretación de las Leyes Fundamentales franquistas en virtud de la cual podría aprovecharse el «potencial democrático" del régimen limitando el poder del jefe del Estado, desarrollando el control de las Cortes sobre el Ejecutivo y transformando la representación orgánica en una representación de corte liberal ${ }^{60}$.

De lo que se trataba, en cualquier caso, era de apostar por una democratización del sistema manteniendo, no obstante, la continuidad institucional y legal del régimen. En la famosa expresión del flamante presidente de las Cortes tras la muerte de Franco, Torcuato Fernández-Miranda, se buscaba aplicar el principio «de la ley a la ley»: las reformas debían llevarse a cabo jurídicamente, sin quiebra del sistema legal, de manera que la democracia surgiese como consecuencia necesaria de modificaciones legales de las instituciones del franquismo. Se evitaría así el contraejemplo portugués, en el que el colapso del Estado tras la «revolución de los claveles» y el consiguiente vacío de poder habían dado lugar a importantes desórdenes públicos (ocupaciones de tierras y fábricas, ataques a empresarios) y a una sustitución rápida de las élites políticas ${ }^{61}$.

$Y$ esa era precisamente la misión que tenía encomendada el primer Gobierno de la Monarquía, el cual se propuso realizar una reforma que definiera un marco político en el que se mezclaran las continuidades del ordenamiento franquista con nuevos elementos de matriz democrática. El plan del Ejecutivo presidido por Carlos Arias Navarro, que había sido diseñado por el vicepresidente y ministro de la Gobernación, Manuel Fraga, se basaba en un difícil equilibrio entre la democracia orgánica y la democracia liberal mediante el desdoblamiento de las Cortes en dos Cámaras: un Congreso elegido por sufragio universal, directo y secreto, y un Senado compuesto por miembros cooptados de las «entidades naturales». Para conseguir esto era necesario elaborar, previamente, una ley que regulara el reconocimiento, la existencia y el funcionamiento de los partidos políticos; reformar el Código Penal para que esos partidos se hallaran dentro de la legalidad; aprobar una ley electoral para que pudieran celebrarse elecciones, $y$, en fin, modificar la Ley Constitutiva de las Cortes y la Ley de Principios del Movimiento Nacional con el objetivo de que el Congreso y el Senado acogieran esa nueva representación popular ${ }^{62}$.

59 Herrero de Miñón (1972: 119).

60 De Esteban et al. (1973).

61 Como explica Sánchez Cervelló (1995: 309), el intento de evitar la deriva portuguesa consistió en que «las clases dirigentes fuesen los árbitros del proceso».

62 Giménez Martínez (2014: 177). 
Ante la inminente llegada de estos proyectos a la Cámara, el GPI decidió formar grupos de trabajo para el estudio de cada uno de los temas afectados: el primero de ellos, compuesto por Gabriel Cisneros, Carlos Iglesias Selgas, Rafael de Mendizábal y José Luis Meilán, se centraría en el derecho de reunión y manifestación; dentro de la Comisión de Competencia Legislativa trabajarían Gabriel Cisneros y Rubens Henríquez; del derecho de asociación se ocuparían Carlos Iglesias Selgas y Rafael de Mendizábal, y sobre asuntos económicos lo harían Baldomero Fernández Calviño, José Elías Gallegos, Rafael Mateo y Josep Melián.

Fruto del trabajo de estos grupos fue la elaboración de unas «líneas directrices» que debían seguir los miembros del Grupo para presentar las enmiendas al proyecto de Ley de Asociaciones Políticas, enviado por el Gobierno a la Cámara en marzo de $1976^{64}$. Un proyecto que, aunque no era «objetivamente rechazable», debía ser «mejorado considerablemente para posibilitar que participen en la próxima convocatoria electoral todas las agrupaciones o partidos políticos que se comprometan a respetar la libertad y la democracia». En este sentido, se insistía en la necesidad de que la expresión "partidos políticos» apareciera no solo en el preámbulo, sino en el articulado de la ley, y de que hubiera un «reconocimiento expreso del derecho que tienen los españoles a afiliarse libremente a partidos políticos para contribuir democráticamente a la determinación de la política nacional». Asimismo, había que levantar todo "control administrativo»y la potestad sancionadora atribuida al Ministerio de la Gobernación: la Administración debía «limitarse a ejercer las funciones de registro» y la sanción «ser exclusivamente judicial». Tampoco podía haber «asociaciones ilegales» de antemano, pues esa decisión había de corresponder a los tribunales. Por último, en cuanto al funcionamiento interno de los partidos, el GPI pedía a sus miembros que presentaran enmiendas conducentes a garantizar «el control de recursos por el Tribunal de Cuentas, [...] la democratización de la organización interna de cada partido y, de manera especial, de sus órganos de gobierno y dirección $»^{65}$.

El GPI alentó la reforma política también en los aspectos estrictamente procedimentales. Así, cuando en abril de 1976 Torcuato Fernández-Miranda estableció el procedimiento de urgencia de tramitación parlamentaria, que pretendía impedir cualquier posible maniobra dilatoria de los inmovilistas ${ }^{66}$,

63 "Contacto 28», Madrid, 3 de marzo de 1976. AESL, carpeta GPI.

64 BOCE, 1492, de 24 de marzo de 1976, pp. 36 048-36055.

65 «Contactos 33 y 34», Madrid, 8 de abril de 1976. AESL, carpeta GPI.

66 BOCE, 1499, de 23 de abril de 1976, pp. 36 317-36 319. Desde ese momento, los proyectos de ley urgentes no se debatirían en la Comisión correspondiente como hasta 
el Grupo envió un comunicado en el que manifestaba su «satisfacción» por el hecho de que se recogiera lo solicitado en su proposición de ley de mayo de 1975 , sobre revalorización de las sesiones plenarias de las Cortes, y consideraba que «el procedimiento arbitrado posibilita el tener en cuenta la existencia de los diversos Grupos Parlamentarios para reconocer a estos, sean o no enmendantes a la totalidad de cada proyecto, la posibilidad de participar mediante portavoces debidamente autorizados, en la discusión o debate general de los proyectos ${ }^{67}$.

Sin embargo, las maniobras de Fernández-Miranda no se vieron acompańadas por una acción acompasada a cargo del Gobierno. Arias nunca fue capaz de imprimir una dirección clara a su proyecto, que, por seguir el incrementalismo de Fraga, resultaba demasiado fragmentario, lo que facilitó el surgimiento y desarrollo de una corriente opositora entre los inmovilistas que alarmó a los reformistas; entre ellos al rey, quien terminó por cesarle ${ }^{68}$. En todo caso, el modelo de reforma Arias-Fraga solo efectuaba modificaciones con voluntad de permanencia en ciertos segmentos del ordenamiento político y habría creado «un sistema híbrido, a la vez complejo y difuso, con muy escasas posibilidades de consolidación ${ }^{69}$. El fracaso de su antecesor hizo que el nuevo Gobierno presidido por Adolfo Suárez modificara el planteamiento de la reforma. El camino tomado desde julio de 1976 consistió en aprobar una norma, casi transitoria ${ }^{70}$, que posibilitara la continuación de las reformas por parte de unas Cámaras legitimadas democráticamente. Fue así como nació la idea de la Ley para la Reforma Política (LRP), octava Ley Fundamental que, de hecho, derogaba sus siete predecesoras ${ }^{71}$.

Antes de la presentación pública del proyecto de LRP, el 6 de septiembre de 1976, dos miembros del GPI, Julián Muro y David Pérez Puga, se reunieron con Suárez y el vicepresidente del Gobierno, Alfonso Osorio, para tratar

entonces, sino que serían informados por una Ponencia propuesta por el presidente de aquella. El procedimiento de urgencia, conocido como el «torcuatazo», generó un repudio casi inmediato entre los procuradores afines al «búnker», que firmaron una carta de rechazo y llegaron a amenazar con promover ante los tribunales un recurso de contrafuero contra él. Véase Powell (1991: 162).

67 "Contacto 35», Madrid, 22 y 23 de abril de 1976. AESL, carpeta GPI.

68 Sánchez-Cuenca (2014: 157-158).

69 Powell (2001: 50).

70 Una auténtica «ley-puente, que permitió el paso pacífico de la legalidad franquista a la legalidad democrática», a juicio de De Esteban y López Guerra (1983: 15).

71 Véanse sobre la LRP las obras de Lucas Verdú (1976), González Navarro (1977) y Sánchez Navarro (1990). 
sobre la «reforma constitucional $»^{72}$. La coincidencia entre los interlocutores «sobre el fondo y la instrumentación de la reforma» fue "casi absoluta». En el encuentro se puso de manifiesto que el GPI había sido «el único que había tratado este tema con rigor y con oportunidad» y tanto Suárez como Osorio reconocieron que sus iniciativas les «habían servido de pauta para tomar decisiones».

Por lo demás, los representantes del Grupo apostaron por una reforma no exclusivamente procedimental, sino sustantiva, «breve y clara», promulgada "con la mayor urgencia», de modo que «la mayoría de los ciudadanos [...] pudiera tomar criterio sobre la decisión política que hayan de adoptar, ya que hasta la fecha están sumidos en el más profundo confusionismo, pudiendo pivotar hacia cualquiera de las tendencias políticas». En íntima conexión con la reforma constitucional se habló de la futura ley electoral. Ambas partes descartaron el sistema de distritos unipersonales, por correr el riesgo de generar «un bipolarismo político que se concretaría en un frente nacional y en otro popular». El GPI se inclinaba bien por un sistema de segunda vuelta bien por «un sistema proporcional con correcciones». En todo caso, «se hizo especial hincapié en reconocer el voto a los mayores de 18 ańos», como se había apuntado en alguna iniciativa anterior, posición que «en principio sorprendió» a Suárez y Osorio, pero que consideraban «con cierta posibilidad de viabilidad». En cuanto al ritmo de los acontecimientos, hubo coincidencia en que «si bien no debería llegarse a un proceso de ruptura», sí debía optarse por una «fórmula intermedia» que fuera más allá de la «simple reformista continuista», que se traduciría en «un sistema constituyente encajado en la legalidad vigente».

Una vez hecho público el contenido de la LRP, el GPI publicó una nota de prensa $^{73}$ en la que mantenía «su criterio favorable al proyecto», porque entendía que servía «al deseo de que el pueblo pueda expresar su voluntad de cara al futuro democrático de los españoles, a través de unas elecciones libres». Además, en la misma recordaba «su postura de un exigente avance hacia la convivencia democrática», en virtud de la cual anunciaba la formulación de «diversas enmiendas, entre otras las conducentes a que el referéndum y el proceso electoral se vean asistidos de las máximas garantías, en orden a una total libertad de expresión y autenticidad de sus resultados».

72 «Nota-informe sobre la reunión sostenida por los representantes del Grupo Parlamentario Independiente, Sres. Muro Navarro y Pérez Puga, con el presidente y vicepresidente del Gobierno», Madrid, 6 de septiembre de 1976. AESL, carpeta GPI.

73 «Nota para los medios de comunicación social», Madrid, 20 de octubre de 1976. AESL, carpeta GPI. 
Cercana ya la convocatoria del Pleno donde se discutiría la LRP, el 27 de octubre de 1976 se celebró una nueva reunión del Grupo ${ }^{74}$ en la que se encargó a Carlos Iglesias Selgas, José Luis Meilán, David Pérez Puga y Antonio Segovia la formulación de las observaciones generales al proyecto, «en la línea de apoyo" al mismo, "pero tratando de mejorarlo en orden a reconocer el derecho de sufragio a los mayores de 18 ańos, atribuir al rey y a las Cortes la iniciativa de la reforma constitucional, la posibilidad de disolución de las Cortes, la soberanía de las Cámaras en materia legislativa y la instrumentación de garantías suficientes, a cargo del poder judicial, para el proceso electoral».

Las ocho observaciones elaboradas por este equipo y hechas suyas por el conjunto del $\mathrm{Grupo}^{75}$ tenían por objeto dar «mayor coherencia y precisión» a la reforma política e «insertar la norma lo más cerca posible de las Constituciones europeas». En primer lugar, se manifestaba la «necesidad de una exposición de motivos que clarifique la voluntad del legislador». En este sentido, se consideraba esencial que en ella apareciera el «reconocimiento de las autonomías regionales y locales», "la aplicabilidad directa de los derechos fundamentales del ciudadano» y «la responsabilidad del Gobierno ante las Cortes». En segundo, la conveniencia de otorgar el sufragio a los mayores de 18 ańos, «dada la madurez, la responsabilidad y la inquietud política de la juventud española». En tercero, el reconocimiento de representación en el Senado a las "colectividades de espańoles fuera de España», que han cargado con «la pesada carga de la emigración». En cuarto, clarificar que la iniciativa de reforma constitucional corresponde no en exclusiva al Gobierno, sino también a las Cámaras. En quinto, introducir el principio de disolución de las Cortes, «básico en todo sistema parlamentario»: "cuando se produzca la imposibilidad de gobernar», el rey debe poder disolver el Parlamento a propuesta del presidente del Gobierno y oídos los presidentes de ambas Cámaras. En sexto, un sistema electoral en el que «deberá mantenerse el principio de representatividad proporcional para el Congreso, matizado para evitar la excesiva proliferación de partidos, y el mayoritario para el Senado». En séptimo, reafirmar la «soberanía de las Cortes» y limitar «las excepciones a este principio» contenidas en el apartado $1^{\circ}$ de la disposición transitoria $2^{\mathrm{a}}$. Y en octavo y último, la introducción de un organismo "para la defensa de la constitucionalidad de las leyes y para velar por la regularidad electoral».

74 "Acuerdos adoptados en la reunión celebrada el día 27 de octubre de 1976», s. 1., s. f. AESL, carpeta GPI.

75 "Observaciones generales al proyecto de Reforma Política», Madrid, 30 de octubre de 1976. AESL, carpeta GPI. 
Aunque estas observaciones fueron defendidas en el Pleno de las Cortes en que se aprobó la $\mathrm{LRP}^{76}$ por David Pérez Puga (pp. 72-76), otros procuradores miembros del Grupo intervinieron en la sesión para reforzar sus planteamientos. Este fue el caso de Carlos Iglesias Selgas (pp. 42-44), José Luis Meilán (pp. 114-119), Andrés Segovia (pp. 119-121), Jesús Aparicio Bernal (pp. 121-125), Gabriel Cisneros (pp. 125-128), Josep Meliá (pp. 128-131) y Rubens Henríquez (pp. 131-132), que formularon sus propias enmiendas individuales. A la hora de la votación, todos los miembros del GPI presentes en el hemiciclo lo hicieron a favor de la ley ${ }^{77}$.

Tras la aprobación de la LRP, el GPI no abandonó su actividad y menudearon las reuniones para fijar su posición ante las normas electorales dictadas en marzo de 1977 y la Ley de Regulación del Derecho de Asociación Sindical, última que aprobarían las Cortes franquistas. Incluso se formó una comisión especial, compuesta por Antonio Castro Villacañas, Jesús Aparicio Bernal, Jesús Sancho Rof, Rubens Henríquez y David Pérez Puga, para «analizar la actitud política del Grupo Parlamentario Independiente de cara a las próximas elecciones», que se reunió el 23 de febrero de 1977. Sin embargo, los miembros del GPI estaban ya más preocupados por resituarse en el nuevo panorama partidista que se abría de cara a la convocatoria electoral del 15 de junio. Así, muchos de sus integrantes impulsaron proyectos políticos propios como la Acción Regional Extremeña de Enrique Sánchez de León, el Partido Gallego Independiente de José Luis Meilán y David Pérez Puga o el Partit Nacionalista Mallorquí de Josep Meliá, y se desvincularon de la actividad del Grupo durante los primeros meses de 1977.

La mayor parte de los procuradores del Grupo se embarcaron en la Federación Social Independiente (FSI), encabezada por Rodolfo Martín Villa. En una reunión celebrada el 3 de marzo de 1977, el GPI decidió «apoyar la formación del nuevo partido y que algunos de sus miembros, no afiliados a otros partidos, encabezaran el grupo promotor de la Federación Social Independiente» ${ }^{78}$. De hecho, el documento fundacional de la FSI surgió precisamente en el seno del Grupo Parlamentario. El «Manifiesto de los socialdemócratas

76 Todas las páginas que se citan entre paréntesis en el texto proceden de BOCE, DSP, 29, de 16, 17 y 18 de noviembre de 1976, pp. 1-207.

77 Estuvo ausente José Manuel Liaño Flores.

78 «Reunión del Grupo Parlamentario Independiente en el Palacio de Congresos y Exposiciones, 3 de marzo de 1977», Madrid, 10 de marzo de 1977. AESL, carpeta GPI. Estos procuradores eran, aparte de Martín Villa, Rubens Henríquez, Paulino Buchens, José Miguel Ortí Bordás, Antonio Castro Villacañas, Daniel Regalado, José María Socías, Francisco Guerrero, Rafael Mateo Tarí, Gabriel Cisneros y Jesús Sancho Rof. Véase El Pais, 5-3-1977, p. 13. 
independientes» pretendía dar voz a la «mayoría de españoles que deseamos se lleve a cabo una avanzada reforma que [...] concluya en una España plenamente democrática» e iba dirigido a «todos aquellos que, por ser partidarios de una profunda reforma [...] no se encuentran identificados por los partidos últimamente surgidos que se plantean como objetivo un continuismo levemente modificado de la situación $»^{79}$.

Al final, tanto estos como aquellos terminarían engrosando las filas de Unión de Centro Democrático (UCD). Así, 21 de los 27 miembros del GPI que continuaron en la vida política lo hicieron dentro de la órbita de esta formación ${ }^{80}$. Muchos revalidaron su acta parlamentaria en las nuevas Cortes democráticas dentro de las candidaturas de $\mathrm{UCD}^{81}$ : fue el caso de Félix Calvo (senador por Guadalajara), Gabriel Cisneros (diputado por Soria), Baldomero Fernández Calviño (senador por La Coruña), Martín Fernández Palacio (senador por Vizcaya), Rubens Henríquez (diputado por Santa Cruz de Tenerife), Rodolfo Martín Villa (senador por designación real) ${ }^{82}$, Ángel Martínez Fuertes (senador por León), José Luis Meilán (diputado por La Coruña), José Miguel Ortí Bordás (diputado por Castellón) ${ }^{83}$, David Pérez Puga (senador por Pontevedra), Antonio Rosón (diputado por Lugo), Enrique Sánchez de León (diputado por Badajoz) ${ }^{84}$ y Jesús Sancho Rof (diputado por

79 «Manifiesto de los socialdemócratas independientes», s. f. AESL, carpeta GPI.

80 Los siete restantes desarrollaron una variopinta y, por lo general, breve carrera política. Jesús Ezponda se presentó como independiente a las elecciones de 1977, pero no resultó elegido, si bien luego fue diputado foral navarro en 1979; Alberto Jarabo se integró en Alianza Popular (AP), partido por el que fue diputado (votó en contra del proyecto de Constitución) y consejero preautonómico de Turismo en Valencia; José Manuel Martínez Aguirre se adscribió a Unió Valenciana y fue diputado autonómico en la década de los ochenta dentro de Coalición Popular; Antonio Navarro pasó a AP, partido por el cual fue diputado en 1982 y europarlamentario en 1987; Javier Perea también ingresó en AP y se presentó a las elecciones por la circunscripción de Orense, pero no salió elegido; y José María Socías, alcalde de Barcelona y senador real, se adscribió al Grupo de Entesa dels Catalans.

81 La continuidad de los procuradores franquistas en las legislaturas democráticas puede seguirse a través de los anexos 14 y 15 de Giménez Martínez (2012: 389-410). Véase también Giménez Martínez (2015).

82 En los sucesivos gabinetes de UCD sería ministro del Interior (1977-1979) y de Administración Territorial (1980-1981), así como diputado por León (1979-1982) y vicepresidente del Gobierno (1981-1982).

83 Aunque resultó elegido dentro de una candidatura independiente, se integró en el Grupo Parlamentario de UCD en el Congreso de los Diputados.

84 Fue también ministro de Sanidad y Seguridad entre 1977 y 1979. 
Pontevedra $)^{85}$. Otros no llegaron a alcanzar un escaño, pero fueron destinados a puestos de responsabilidad en diversos niveles de la Administración: Paulino Buchens y Abelardo Sánchez fueron nombrados alcaldes de Palma de Mallorca y Albacete, respectivamente; Francisco Guerrero, director general de la Función Pública y presidente de la Comisión Liquidadora de Organismos; José Manuel Liaño permaneció como alcalde de La Coruña hasta las elecciones municipales de 1979; José Lladó dejó la cartera de Comercio para dirigir el Ministerio de Transportes y Comunicaciones ${ }^{86}$; Josep Meliá fue nombrado secretario de Estado de Información y, con posterioridad, gobernador general de Cataluña; Eduardo Navarro fue designado subsecretario de Interior y Daniel Regalado quedó como gerente de servicios del Instituto Nacional de la Salud en 1981.

\section{CONCLUSIONES}

Los políticos moderados que formaban parte del régimen de Franco en los años setenta y que apoyaban la reforma del sistema político fueron un importante factor para el éxito de la transición democrática en España. Fueron estos reformistas del franquismo los que ayudaron al rey Juan Carlos, Adolfo Suárez y Torcuato Fernández-Miranda a poner en práctica los proyectos de reforma política y quienes contribuyeron, decisivamente, a la transformación política del país, colaborando al alumbramiento de una democracia desde la legalidad vigente. Dentro de las Cortes, los reformistas se unieron en torno al Grupo Parlamentario Independiente, que se definió desde su constitución a favor del proceso democratizador de las estructuras políticas. Durante el breve tiempo en que desarrolló su actividad sus miembros propiciaron programas de reforma y se sumaron al consenso mayoritario para lograr la transición democrática sin traumas que los cambios socioeconómicos de España exigían.

Los planteamientos que el GPI vino formulando tenían un claro sentido pragmático y partían de la experiencia de los cuarenta ańos anteriores, como no podía ser de otra manera en figuras que habían desarrollado su carrera política al amparo de la dictadura. Pero esto, siendo rigurosamente cierto, no les llevó a la conclusión de que, tras la muerte de Franco, había que continuar con su régimen. La fidelidad de los miembros del GPI a su pasado era

\footnotetext{
85 Subsecretario de Interior en 1978 y 1979, ocupó luego las carteras ministeriales de Obras Públicas (1979-1981) y Trabajo y Sanidad (1981).

86 En 1979 se le enviaría como embajador a Washington.
} 
proyectiva, es decir, implicaba el convencimiento de que, de cara al futuro, en las cuestiones públicas habría que tener en cuenta necesariamente al conjunto de los ciudadanos y no podrían imponerse, como hasta entonces, proyectos políticos no compartidos. Desde este planteamiento, el Grupo introdujo en todas sus iniciativas parlamentarias elementos de cambio político, basados en una realidad social y económica que había variado aceleradamente en los años precedentes y exigía un marco democrático de convivencia.

El GPI apostó por una reforma política capaz de acallar las querellas históricas y conseguir una reconciliación entre los españoles; un proyecto que pudiera realizarse en la libertad, en la justicia y en el respeto a la diversidad. La edificación de una sociedad pluralista excluía el inmovilismo de la misma forma que debía hacer inútil la revolución. De ahí que el Grupo rechazara la ruptura con toda la secuela de abrir un proceso constituyente, que consideraba ilimitado e incontrolable. No ponían en cuestión, por tanto, la legitimidad del Estado franquista, pero entendían que a partir de él debía abrirse un proceso de reforma que viabilizara la transformación del sistema autoritario en otro democrático y que respondiera a los postulados de auténtica soberanía del pueblo español. Un proceso que no podía adoptar la forma plebiscitaria de alternativa entre dictadura y democracia, sin pasar antes por la legalidad que establecían las instituciones vigentes.

Los planteamientos sobre la reforma mantenidos por el Grupo (articulados a través de mociones, ruegos, proposiciones de ley, cartas o comunicados) se pueden sintetizar en cuatro puntos fundamentales. El primero de ellos se basaba en la aplicación directa de los derechos fundamentales por los órganos del Estado. El segundo, en la elección por sufragio universal de las Cámaras que en el día de mañana hubieran de componer las Cortes. El tercero, una garantía jurisdiccional de la Constitución y del proceso electoral a través de un Tribunal de Garantías. Y el cuarto, una revisión de las Leyes Fundamentales más definida y menos ligada a cuestiones procedimentales, que tuviera como resultado una Constitución democrática de corte occidental.

La corta pero intensa actividad del Grupo llegó a alcanzar una resonancia y una influencia políticas sumamente valiosas para el triunfo de la estrategia reformista, que se puso de manifiesto a la hora de tener que aprobar la Ley para la Reforma Política. El proyecto presentado por el Gobierno Suárez coincidía en su filosofía básica con la idea de reforma que venía propiciando el GPI. Y, como consecuencia de ello, llegado el momento de su discusión en las Cortes, sus integrantes lo apoyaron eficazmente. En definitiva, los movimientos del Grupo Parlamentario Independiente aportaron notas positivas al proceso democratizador, dinamizaron y abrieron la vida pública española y contribuyeron mucho a la sensibilización de los ciudadanos respecto al desafío que comportaría necesariamente el postfranquismo. 


\section{Bibliografía}

Aguiló Lúcia, Ll. (1976). Los grupos parlamentarios (Notas para su regulación en España). Cuadernos de la Cátedra Fadrique Furió Ceriol, 2, $27-56$.

Álvarez de Miranda, F. (1985). Del «contubernio» al consenso. Barcelona: Planeta.

Areilza, J. M. de (1977). Diario de un ministro de la Monarquía. Barcelona: Planeta.

Baena del Alcázar, M. (1999). Élites y conjuntos de poder en España (1939-1992). Un estudio cuantitativo sobre Parlamento, Gobierno y Administración y gran empresa. Madrid: Tecnos.

Bañón Martínez, R. (1978). Poder de la burocracia y Cortes franquistas, 1943-71. Madrid: Instituto Nacional de Administración Pública.

Carr, R. y Fusi, J. P. (1979). España, de la dictadura a la democracia. Barcelona: Ariel.

De Esteban, J. et al. (1973). Desarrollo politico y Constitución española. Barcelona: Ariel.

- y López Guerra, L. (1983). El régimen constitucional español, vol. I. Barcelona: Labor.

De Miguel, A. (1975). Sociología del franquismo. Análisis ideológico de los ministros del régimen. Barcelona: Euros.

Díaz-Nosty, B. (1972). Las Cortes de Franco. 30 años orgánicos. Barcelona: Dopesa.

Fernández Carvajal, R. (1967). Las Cortes Españolas en la Ley Orgánica del Estado. Revista de Estudios Políticos, 12, 57-95.

— (1969). La Constitución Española. Madrid: Editora Nacional.

Fernández Sarasola, I. (2012). Reglamentos parlamentarios (1810-1977). Madrid: Iustel.

Fernández Segado, F. (1986). Las Constituciones históricas españolas: un análisis histórico-jurídico. Madrid: Civitas.

Fernández-Miranda, P. y Fernández-Miranda, A.(1995). Lo que el Rey me ha pedido. Torcuato Fernández-Miranda y la reforma política. Barcelona: Plaza y Janés.

Ferrando Badía, J. (1984). El régimen de Franco. Un enfoque politico-jurídico. Madrid: Tecnos.

Fraga Iribarne, M. (1959). El Reglamento de las Cortes Españolas. Madrid: Servicio de Información y Publicaciones de la Organización Sindical.

- (1971). El desarrollo politico. Barcelona: Grijalbo.

- (1980). Memoria breve de una vida pública. Barcelona: Planeta.

García Guerrero, J. L. (1996). Democracia representativa de partidos y grupos parlamentarios. Madrid: Congreso de los Diputados.

Garrorena Morales, Á. (1977). Autoritarismo y control parlamentario en las Cortes de Franco. Murcia: Universidad de Murcia.

Giménez Martínez, M. Á. (2012). Las Cortes Españolas en el régimen de Franco. Madrid: Congreso de los Diputados.

- (2014). El Estado franquista. Fundamentos ideológicos, bases legales y sistema institucional. Madrid: Centro de Estudios Políticos y Constitucionales.

- (2015). Un Parlamento en transición. Las Cortes Constituyentes, 1977-1979. Madrid: Universidad Autónoma de Madrid. Disponible en: https://doi.org/10.15366/cortesconst7779.2015.

González Navarro, F. (1977). La nueva Ley Fundamental para la Reforma Politica. Madrid: Servicio Central de Publicaciones de Presidencia del Gobierno. 
Herrero de Miñón, M. (1972). El principio monárquico. Madrid: Edicusa.

Hispán Iglesias de Ussel, P. (2006). La política en el régimen de Franco entre 1957 y 1969. Proyectos, conflictos y luchas por el poder. Madrid: Centro de Estudios Políticos y Constitucionales.

Iglesias Selgas, C. (1973). Las Cortes Españolas. Pasado, presente y futuro. Madrid: Cabal.

Jerez Mir, M. (1982). Élites políticas y centros de extracción en España, 1938-1957. Madrid: Centro de Investigaciones Sociológicas.

_ (1996). El régimen de Franco: élite política central y redes clientelares. En A. Robles Egea (coord.). Política en penumbra. Patronazgo y clientelismo políticos en la España contemporánea (pp. 253-274). Madrid: Siglo XXI.

Juliá, S. (2010). Hoy no es ayer. Ensayos sobre la España del siglo XX. Barcelona: RBA.

Linz, J. J. (1964). An authoritarian regime: Spain. En E. Allardt e Y. Littunen (eds.). Cleavages, ideologies and party systems: contributions to comparative political sociology (pp. 291-341). Helsinki: The Academic Bookstore.

López Nieto, L. (1988). Alianza Popular: estructura y evolución electoral de un partido conservador, 1976-1982. Madrid: Centro de Investigaciones Sociológicas.

Lucas Verdú, P. (1976). La octava ley fundamental. Crítica jurídico-politica de la reforma Suárez. Madrid: Tecnos.

Martín Villa, R. (1984). Al servicio del Estado. Barcelona: Planeta.

Meliá, J. (1976). Los grupos parlamentarios, peana para el búnker. Discusión y Convivencia, 6, 16-20.

Menéndez Rexach, Á. (1979). La Jefatura del Estado en el Derecho Público español. Madrid: Instituto Nacional de Administración Pública.

Molinero, C. e Ysàs, P. (2008). La anatomía del franquismo. De la supervivencia a la agonía, 1945-1977. Barcelona: Crítica.

Morales Arroyo, J. M. (1990). Los grupos parlamentarios en las Cortes Generales. Madrid: Centro de Estudios Constitucionales.

Negrín, F. L. R. (1976). El Congreso se remoza. Pueblo, 14-2-1976.

Oreja, M. (2011). Memoria y Esperanza. Relatos de una vida. Madrid: La Esfera de los Libros.

Ortí Bordás, J. M. (2009). La Transición desde dentro. Barcelona: Planeta.

Osorio, A. (1980). Trayectoria politica de un ministro de la Corona. Barcelona: Planeta.

Palomares, C. (2006). Sobrevivir después de Franco. Evolución y triunfo del reformismo, 19641977. Madrid: Alianza.

Payne, S. G. (1987). The Franco Regime, 1936-1975. Madison (WI): University of Wisconsin Press.

Pérez-Serrano Jáuregui, N. (1989). Los grupos parlamentarios. Madrid: Tecnos.

Powell, Ch. T. (1990). The «Tácito» Group and the Transition to Democracy, 1973-1977. En F. Lannon y P. Preston (eds.). Elites and Power in Twentieth Century Spain (pp. 249-268). Oxford: Clarendon.

- (1991). El piloto del cambio. El rey, la monarquía y la transición a la democracia. Barcelona: Planeta.

- (1997). Crisis del franquismo, reformismo y transición a la democracia. En J. Tusell et al. Las derechas en la España contemporánea (pp. 247-270). Madrid: Anthropos.

(2001). España en democracia, 1975-2000. Barcelona: Plaza y Janés. 
Saiz Arnáiz, A. (1989). Los grupos parlamentarios. Madrid: Congreso de los Diputados.

Sánchez Cervelló, J. (1995). La revolución portuguesa y su influencia en la transición española, 1961-1976. Madrid: Nerea.

Sánchez de León, E. (2008). Los reformistas del franquismo en la transición política. Badajoz: Tecnigraf.

Sánchez Navarro, Á. J. (1990). La transición politica en las Cortes de Franco: hacia la Ley para la Reforma Politica (1975-1976). Madrid: Instituto Juan March.

Sánchez Recio, G. (1996). Los cuadros politicos intermedios del régimen franquista, 1936-1959. Diversidad de origen e identidad de intereses. Alicante: Instituto Juan Gil-Albert.

Sánchez-Cuenca, I. (2014). Atado y mal atado. El suicidio institucional del franquismo y el surgimiento de la democracia. Madrid: Alianza.

Soto Carmona, Á. (1995). De las Cortes orgánicas a las Cortes democráticas. Ayer, 15, 109134.

- (2005). ¿Atado y bien atado? Institucionalización y crisis del franquismo. Madrid: Biblioteca Nueva.

Torres del Moral, A. (1981). Los grupos parlamentarios. Revista de Derecho Politico, 9, 21-66.

Tusell, J. (2005). La España de Franco. El poder, la oposición y la politica exterior durante el franquismo. Madrid: Albor.

Viver Pi-Sunyer, C. (1978). El personal politico de Franco (1936-1945). Contribución empírica a una teoría del régimen franquista. Barcelona: Vicens Vives.

Zafra Valverde, J. (1973). Régimen político de España. Pamplona: Eunsa. 